\title{
Pengembangan Media Pembelajaran Fisika Menggunakan Game Edukasi Pada Kelas Xi Di Madrasah Aliyah Nurul Hidayah Bojonegara
}

\author{
Budi Santosa \\ Program Studi \\ Pendidikan Vokasional \\ Teknik Elektro FKIP \\ Universitas Sultan \\ Ageng Tirtayasa Serang, \\ Indonesia \\ Budhi040796@gmail.com
}

\author{
Didik Aribowo \\ Program Studi \\ Pendidikan Vokasional \\ Teknik Elektro FKIP \\ Universitas Sultan \\ Ageng Tirtayasa Serang, \\ Indonesia \\ d_aribowo@untirta.ac.id
}

\author{
Irwanto \\ Program Studi \\ Pendidikan Vokasional \\ Teknik Elektro FKIP \\ Universitas Sultan \\ Ageng Tirtayasa Serang, \\ Indonesia \\ irwanto.ir@untirta.ac.id
}

\begin{abstract}
Verbal delivery of learning and long learning hours causes students to often play games without the knowledge of the teacher during the learning process so that learning outcomes are not optimal to achieve the specified minimum completeness criteria. This study aims to produce educational game learning media and determine student responses to educational game learning media. To be able to produce a certain product, the research steps used the waterfall model. This research was conducted at Madrasah Aliyah Nurul Hidayah Bojonegara in class XI students with data sources on learning outcomes dan syllabus. Data collection techniques used interviews, observation and questionnaires, while data analysis techniques used a likert scale. The results of the research to be achieved are a jigsaw puzzle game as a learning medium, this game is made using the Unity $3 D$ application. from the study also wanted to know student responses about the jigsaw puzzle game as an educational game or learning media.
\end{abstract}

Keywords: Jigsaw Puzzle Game, Learning Media, Waterfall.

\section{Pendahuluan}

Pendidikan merupakan proses yang komplek, namun kompleksitasnya selalu seiring dengan perkembangan manusia. Pendidikan menurut UU No. 20 Tahun 2003 pasal 3 tentang sistem Pendidikan Nasional tujuan Pendidikan adalah untuk mengembangkan potensi peserta didik agar menjadi manusia yang beriman dan berakhlak mulia, sehat, berilmu, cakap, kreatif, mandiri, dan menjadi warga negara yang demokratis serta bertanggung jawab [1].

Melalui pendidikan pula berbagai aspek kehidupan dikembangkan lewat proses belajar dan pembelajaran. Berbagai masalah dalam proses belajar perlu diselaraskan dan distabilkan agar kondisi belajar tercipta sesuai dengan tujuan yang ingin dicapai serta dapat diperoleh seoptimal mungkin. Untuk melengkapi komponen belajar dan pembelajaran di sekolah, sudah seharusnya guru memanfaatkan media atau alat bantu yang mampu merangsang pembelajaran secara efektif dan interaktif.
Berkenaan dengan komponen-komponen pembelajaran di dalamnya memiliki fungsi yang saling berkaitan dengan komponen lainnya. Didalam pembelajaran terdapat sebuah proses belajar atau interaksi atau disebut juga proses komunikasi yang dibangun antara guru dengan siswa. Di dalam proses komunikasi inilah peranan media pembelajaran dapat difungsikan [6].

Penggunaan media pembelajaran merupakan bagian yang tidak bisa dipisahkan dan sudah merupakan suatu integrasi terhadap metode belajar yang dipakai. Media pembelajaran untuk belajar mandiri pada era kemajuan teknologi sangat dibutuhkan dalam proses pembelajaran. Hal ini dibutuhkan untuk menciptakan suasana belejar yang tidak hanya bergantung melalui transfer ilmu secara verbal.

Penerapan media pembelajaran di kelas mampu meningkatkan motivasi belajar siswa sehingga media tersebut dapat menunjang

Dalam proses belajar mengajar penggunaan media pembelajaran yang berupa media visual dapat berpengaruh positif dimana hal tersebut dibuktikan dengan hasil belajar siswa yang meningkat setelah diberikan perlakuan menggunakan media pembelajaran visual [2]. Penggunaan media pembelajaran berupa technology based mampu meningkatkan efektifitas selama proses belajar mengajar sehingga penyampaian materi oleh pendidik menjadi terbantu dengan diterapkannya suatu media pembelajaran berupa technology based, Media pembelajaran juga membuat lingkungan belajar mengajar menjadi lebih menarik dan meningkatkan pemahaman siswa dalam belajar [5].

\section{TEORI DASAR}

Pendidikan merupakan proses yang komplek, namun kompleksitasnya selalu seiring dengan perkembangan manusia. Pendidikan menurut UU No. 20 Tahun 2003 pasal 3 tentang sistem Pendidikan Nasional tujuan Pendidikan adalah untuk mengembangkan potensi peserta didik agar menjadi manusia yang beriman dan berakhlak mulia, sehat, berilmu, cakap, kreatif, mandiri, 
dan menjadi warga negara yang demokratis serta bertanggung jawab [5].

Media pembelajaran adalah media kreatif yang digunakan dalam memberikan materi pelajaran kepada anak didik sehingga proses belajar mengajar lebih efektif, efesien dan menyenangkan [10]. Media pembelajaran memiliki peranan yang besar dan berpengaruh terhadap pencapaian tujuan pendidikan yang diinginkan [7].

Penggunaan media pembelajaran berupa technology based mampu meningkatkan efektifitas selama proses belajar mengajar sehingga penyampaian materi oleh pendidik menjadi terbantu dengan diterapkannya suatu media pembelajaran berupa technology based, Media pembelajaran juga membuat lingkungan belajar mengajar menjadi lebih menarik dan meningkatkan pemahaman siswa dalam belajar [1].

game edukasi yaitu sebuah media pembelajaran yang bersifat mendidik, dimana dengan media dapat mendorong siswa untuk berpikir kreatif dan melakukan kegiatan dengan sesama siswa dalam melakukan permainan kegiatan belajar [9].

Berkenaan dengan komponen-komponen pembelajaran di dalamnya memiliki fungsi yang saling berkaitan dengan komponen lainnya. Didalam pembelajaran terdapat sebuah proses belajar atau interaksi atau disebut juga proses komunikasi yang dibangun antara guru dengan siswa. Di dalam proses komunikasi inilah peranan media pembelajaran dapat difungsikan [6].

Dalam proses belajar mengajar penggunaan media pembelajaran yang berupa media visual dapat berpengaruh positif dimana hal tersebut dibuktikan dengan hasil belajar siswa yang meningkat setelah diberikan perlakuan menggunakan media pembelajaran visual [2]. Game puzzle merupakan permainan atau mainan yang memiliki suatu masalah untuk diselesaikan dengan tujuan mengasah kecerdasan pemain [3].

Unity $3 D$ adalah aplikasi game engine terbaik yang dikembangkan oleh Unity Technologies dan bersifat crossplatform, artinya anda dapat membuat serta merilis game ke berbagai platform terkenal, seperti Windows, Linux, Mac OS, Android, iOs, PS3, PS4, Xbox One, dan lainlain.

penelitian ini penulis menggunakan metode penelitian pengembangan media pembelajaran yaitu dengan metode penelitian pengembangan atau dikenal dengan Research and Development (R\&D) [8].

Penelitian dan pengembangan menggunakan model waterfall, karena model ini salah satu rekayasa perangkat lunak dan lebih sesuai. Model ini dirasa sangat cocok untuk penelitian, karena proses pengembangan ini lebih spesifik ke arah software atau perangkat lunak, dimana penelitian ini bertujuan membuat sebuah game edukasi untuk proses pembelajaran [4].

\section{METODE PENELITIAN}

Metode penelitian pengembangan media pembelajaran yaitu dengan metode penelitian pengembangan atau dikenal dengan Research and Development (R\&D). Penelitian ini bertujuan mengambil kegiatan proses dasar seperti spesifikasi, pengembangan, validasi, dan evolusi dan mempresentasikannya sebagai fase-fase proses yang berbeda seperti spesifikasi persyaratan, perancangan perangakat lunak, implementasi, pengujian dan seterusnya. Dalam penelitian pengembangan ini menggunakan model waterfall. Penelitian dan pengembangan menggunakan model waterfall, karena model ini salah satu rekayasa perangkat lunak dan lebih sesuai. Model ini dirasa sangat cocok untuk penelitian, karena proses pengembangan ini lebih spesifik ke arah software atau perangkat lunak, dimana penelitian ini bertujuan membuat sebuah game edukasi untuk proses pembelajaran. Model Waterfall yang digunakan terdiri dari lima tahapan yaitu : (1) Analisis kebutuhan, (2) desain sistem, (3) penulisan kode program, (4) implementasi dan (5) pemeliharaan. Berikut tahaptahap penelitian pengembangan waterfall dapat dilihat pada Gambar 1 dibawah ini

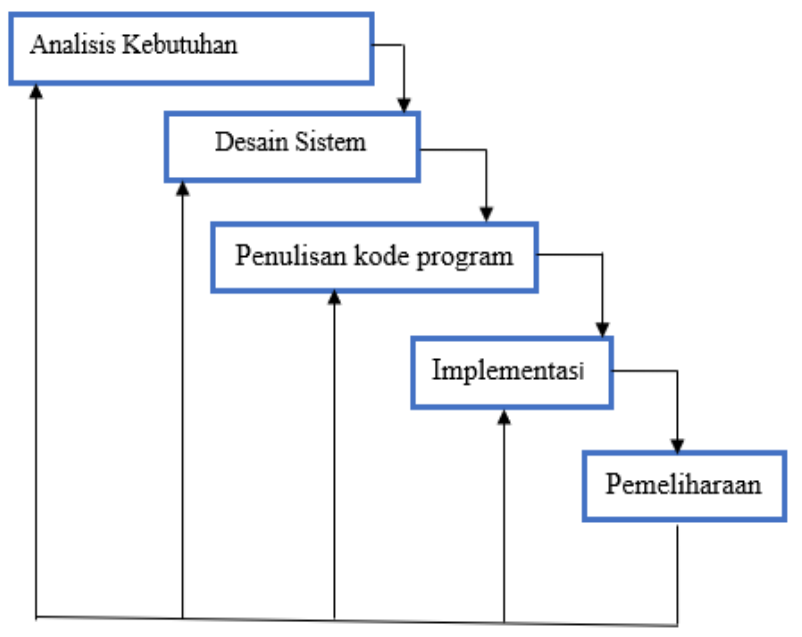

Gambar 1. Model waterfall

Subyek penelitian pengembangan ini adalah peserta didik kelas XI di Madrasah Aliyah Nurul Hidayah Bojonegara sebanyak 30 siswa.

\section{HASIL DAN PEMBAHASAN}

Berdasarkan penelitian yang telah dilaksanakan di Madrasah Aliyah Nurul Hidayah Bojonegara pada kelas XI pengembangan media pembelajaran fisika menggunakan game edukasi didapatkan hasil sebagai berikut:

\section{A. Pengembangan Media Pembelajaran}

Tahap pertama yaitu analisis dan definisi persyaratan. Tahap analisis bertujuan untuk mengetahui keadaan lapangan agar peneliti dapat menyesuaikan tujuan penelitian dengan kebutuhan sekolah. Pada tahap ini, hal yang pertama kali dilakukan oleh peneliti adalah melakukan wawancara mengenai kurikulum yang berlaku dengan guru mata pelajaran fisika di yaitu bapak Suherman, S.T. Kurikulum yang digunakan di sekolah yaitu Kurikulum 2013. pengamatan dasar yang digunakan pada penelitian ini dapat dilihat pada Tabel 1.

\begin{tabular}{|c|c|c|}
\hline \multicolumn{3}{|c|}{ Tabel 1. Pengamatan dasar } \\
\hline $\begin{array}{l}\text { Aspek Yang } \\
\text { Diamati }\end{array}$ & Indikator & Keterangan \\
\hline $\begin{array}{l}\text { Perangkat } \\
\text { pembelajaran }\end{array}$ & $\begin{array}{l}\text { Silabus } \\
\text { Diktat pelajaran }\end{array}$ & $\begin{array}{l}\text { Ada } \\
\text { Ada }\end{array}$ \\
\hline
\end{tabular}




\begin{tabular}{|l|l|l|}
\hline $\begin{array}{l}\text { Kondisi } \\
\text { siswa dikelas }\end{array}$ & Suasana di kelas & $\begin{array}{l}\text { Tenang, } \\
\text { berangsur bosan } \\
\text { dan sembunyi- } \\
\text { sembunyi main } \\
\text { ponsel } \\
\text { Aktif } \\
\text { mengerjakan } \\
\text { tugas, pretest dan } \\
\text { lain-lain }\end{array}$ \\
\hline $\begin{array}{l}\text { Keaktifan siswa } \\
\text { dalam belajar } \\
\text { pembelajaran }\end{array}$ & $\begin{array}{l}\text { Pembukaan } \\
\text { Apersepsi } \\
\text { materi }\end{array}$ & $\begin{array}{l}\text { Ada } \\
\text { Baik } \\
\text { digambarkan }\end{array}$ \\
\hline
\end{tabular}

Tahap kedua yaitu perancangan sistem perangkat lunak. Pada tahap ini dijelaskan rancangan-rancangan yang dibuat untuk menghasilkan media pembelajaran berupa game edukasi yaitu jenis game puzzle. Pada tahap ini terdapat rancangan berupa pembuatan desain game puzzle secara keseluruhan (storyboard). Ketika game puzzle dioperasikan, pada halaman awal terdapat judul game yaitu "game fisika", logo universitas asal peneliti (Universitas Sultan Ageng Tirtayasa), logo sekolah tempat melakukan penelitian (Madrasah Aliyah Nurul Hidayah Bojonegara). Pada menu utama game edukasi ini terdapat beberapa fitur, yaitu "play", "exit", "pengaturan", dan "informasi petunjuk". Untuk lebih jelasnya dapat dilihat pada Gambar 2 dibawah ini.

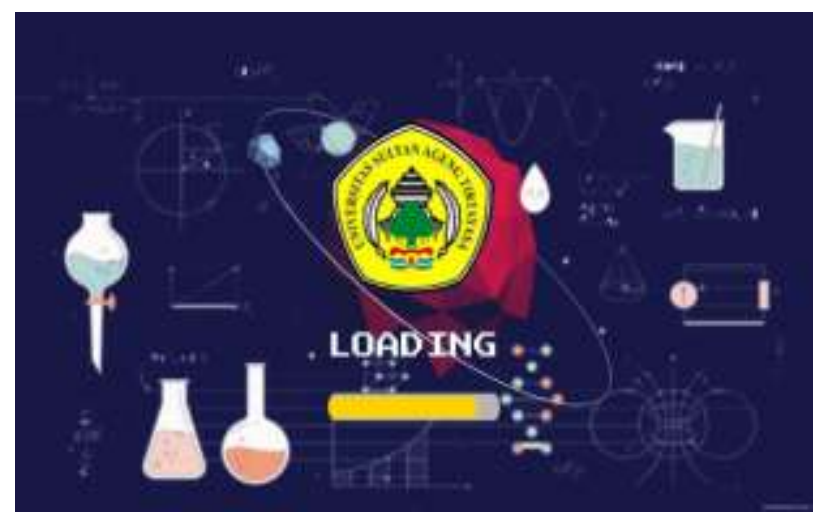

Gambar 2. Tampilan loading

Tampilan saat loading masuk game menampilkan logo Untirta dan icon loading.

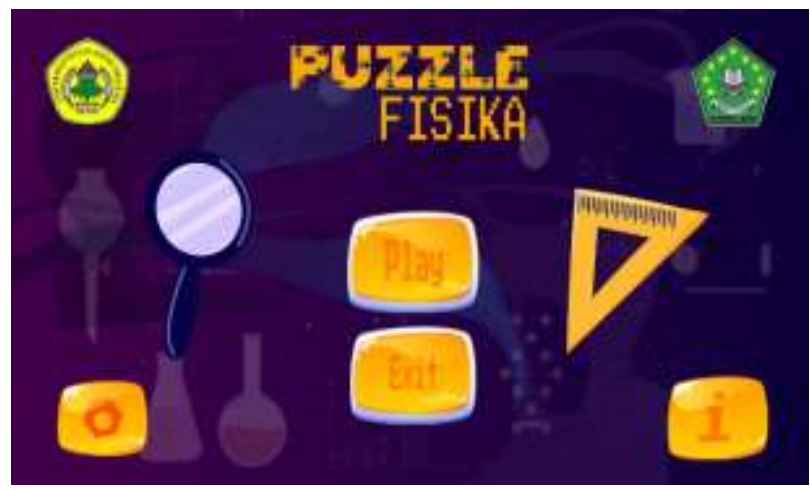

Gambar 3. Tampilan halaman utama

Pada halaman utama ada tombol "play" terdapat tiga pilihan level yang dapat dimainkan oleh pengguna untuk menyelesaikan game puzzle, yaitu Menyusun blok puzzle.

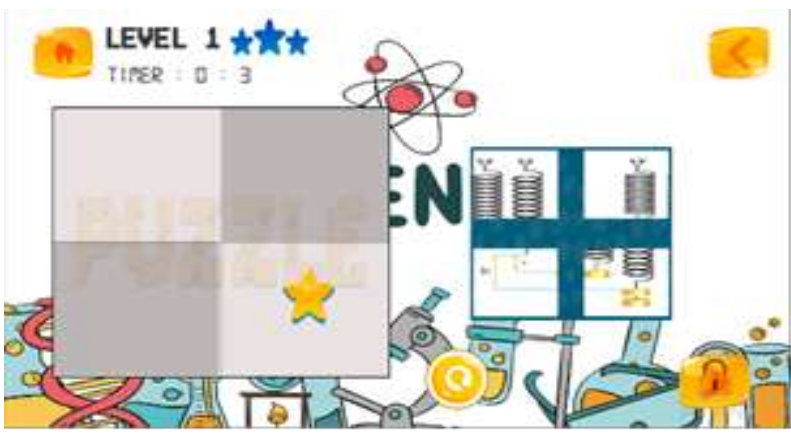

Gambar 4. Halaman permainan

Pada game puzzle ini, terdapat tiga level, setiap level meiliki tiga stage setiap level atau stage memiliki tingkat kesulitan yang berbeda. Cara beramin pada game ini yaitu menggeser potongan puzzle ke sebeluh kanan blok susun puzzle, disusun menjadi gambar yang utuh untuk menyelesaikannya Tampilan halaman Permianan game dapat dilihat pada Gambar 4 diatas. Di akhir permainan setiap level terdapat penjelsan tentang materi fisika yang disusun dalam game puzzle serta ucapan selamat, untuk lebih jelasnya dapat dilihat pada Gambar 5 dibawah ini.

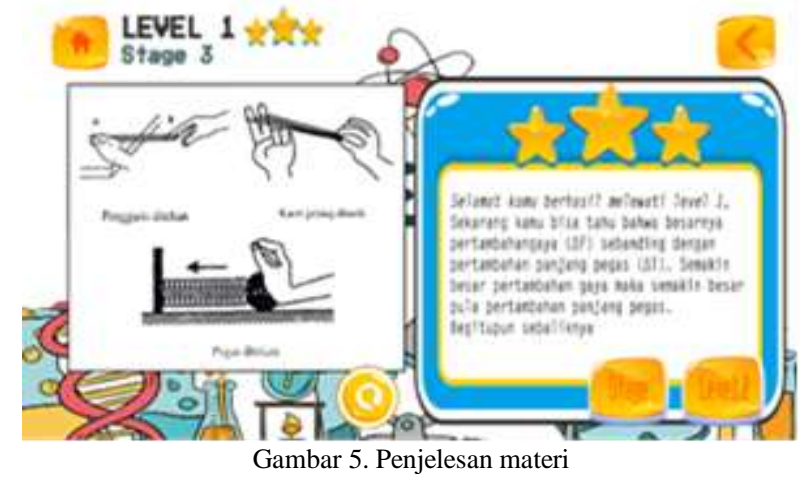

Selamat kamu berhasil melewati level 1. Sekarang kamu bisa tahu besarnya pertambahan gaya sebanding dengan pertambahan Panjang pegas. Semakin besar pertambahan gaya semakin besar pula pertambahan Panjang pegas. Penjelsan ini terdapat di akhir setiap level 1, 2 dan 3. Di akhir permainan game puzzle ini terdapat halaman ucapan selemat puzzle finish dihalaman ini bisa Kembali ke home atau keluar dari aplikasi game puzzle, keterangan ini dapat dilihat pada gambar 6 dibawah ini.

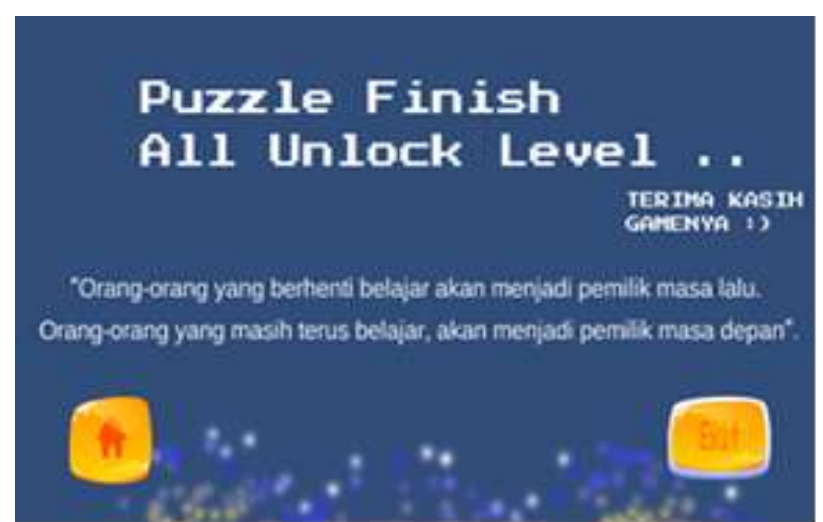

Gambar 6. Halaman akhir game puzzle 


\section{B. Kelayakan Game Edukasi}

kelayakan game edukasi mata pelajaran fisika sebagai media pembelajaran dapat ditinjau dari hasil validasi ahli media dan ahli materi.

1. Penilaian Ahli Media

Validasi oleh ahli media untuk mengetahui kelayakan game edukasi sebagai media pembelajaran yang dibuat oleh peneliti supaya dapat digunakan dengan maksimal. Pengujian ahli media dilakukan oleh dua ahli media yaitu dosen Untirta. Berikut data uji validasi dapat dilihat pada Tabel 2 dibawah ini.

Tabel 2. Penilaian ahli media

\begin{tabular}{|c|c|c|c|}
\hline \multirow[b]{2}{*}{ Butir Pernyataan } & \multicolumn{2}{|c|}{ Validator Ahli Media } & \multirow[b]{2}{*}{$\begin{array}{l}\text { Nilai } \\
\text { Ideal }\end{array}$} \\
\hline & $\begin{array}{c}\text { Ahli } \\
\text { Media } 1\end{array}$ & $\begin{array}{c}\text { Ahli } \\
\text { Media } 2\end{array}$ & \\
\hline 1 & 4 & 4 & \multirow{12}{*}{55} \\
\hline 2 & 5 & 3 & \\
\hline 3 & 5 & 4 & \\
\hline 4 & 5 & 4 & \\
\hline 5 & 4 & 4 & \\
\hline 6 & 4 & 3 & \\
\hline 7 & 5 & 2 & \\
\hline 8 & 4 & 5 & \\
\hline 9 & 5 & 4 & \\
\hline 10 & 5 & 4 & \\
\hline 11 & 5 & 4 & \\
\hline Jumlah & 51 & 41 & \\
\hline
\end{tabular}

Pada tabel diatas ada 11 pernyataan, maka dapat di hitung rata-rata jawaban berdasarkan skoring jawaban ahli media 1 jumlahnya 51 Jumlah skor ideal (kriterium) skor tertinggi $=5 \times 11=55(\mathrm{SS})$ Jumlah skor minimum $=$ $1 \times 11=11$ (TS) Presentase skor $\mathrm{P}=\frac{n}{N} X 100 \%$

$\mathrm{P}=\frac{51}{55} \mathrm{X} 100 \%=92.7 \%$

Berikutnya peniliaian ahli media 2, maka dapat di hitung rata-rata jawaban berdasarkan skoring jawaban jumlahnya 41, Jumlah skor ideal (kriterium) skor tertinggi $=5 \times 11=55(\mathrm{SS})$ Jumlah skor minimum $=1 \times 11=11$ (TS) dengan presentase skor sebagai berikut: $\mathrm{P}=\frac{n}{\mathrm{~N}} \mathrm{X} 100 \%$

$\mathrm{P}=\frac{41}{55} \mathrm{X} 100 \%=74.5 \%$

Dari hasil penskoran ahli media 1 mendapat $92.7 \%$ sedangkan ahli media 2 mendapat $74.5 \%$ maka nilai rataratanya adalah

$$
x=\frac{1}{n} \sum_{i=1}^{n} x_{i}
$$

$\mathrm{P}=\frac{1}{2}(92.7 \%+74.5 \%=83.2 \%$

Secara keseluruhan nilai rata-rata game edukasi memproleh $83.2 \%$, dengan skor tersebut jika melihat pada tabel uji kelayakan termasuk dalam range $76 \%-100 \%$ yaitu sangat layak, penilaian dari dua ahli media menunjukan bahwa game puzzle ini sangat layak.

2. Penilaian Ahli Materi

Penilaian ahli materi bertujuan mengetahui kelayakan isi materi mata pelajaran fisika dengan silabus dan RPP (Rencana Pelaksanaan Pembelajaran) yang berlaku di sekolah Madrasah Aliyah Nurul Hidayah Bojonegara, beikut hasil penilaian ahli materi dapat dilihat pada Tabel 3 dibawah ini.

Tabel 3. penilaian ahli materi

\begin{tabular}{|c|c|c|c|}
\hline Butir Pernyataan & \multicolumn{2}{|c|}{ Validator Ahli Materi } & \multirow{2}{*}{ Nilai } \\
& $\begin{array}{c}\text { Ahli } \\
\text { Materi 1 }\end{array}$ & $\begin{array}{c}\text { Ahli } \\
\text { Materi 2 }\end{array}$ & \\
Ideal \\
\hline 1 & 4 & 5 & \\
\hline 2 & 4 & 5 & \\
\hline 3 & 4 & 4 & \multirow{3}{*}{35} \\
\hline 4 & 5 & 5 & \\
\hline 5 & 5 & 4 & \\
\hline 6 & 5 & 5 & \\
\hline 7 & 5 & 5 & \\
\hline Jumlah & 32 & 33 & \\
\hline & & \multicolumn{2}{|c}{} \\
\hline
\end{tabular}

Pada tabel 3 diatas terdapat 7 butir pernyataan untuk peniliaian ahli materi menilai isi materi yang ada pada game puzzle, maka dapat di hitung rata-rata jawaban ahli materi 1 berdasarkan skor jawaban jumlahnya 32, Jumlah skor ideal (kriterium) skor tertinggi $=5 \times 7=35$ (SS) Jumlah skor minimum $=1$ x $7=7$ (TS) Presentase skor

$\mathrm{P}=\frac{n}{\mathrm{~N}} \mathrm{X} 100 \%$

$\mathrm{P}=\frac{32}{35} \mathrm{X} 100 \%=91 \%$

Berikutnya peniliaian ahli materi 2 , maka dapat di hitung rata-rata jawaban berdasarkan skoring jawaban jumlahnya 33, Jumlah skor ideal (kriterium) skor tertinggi $=5 \times 7=35$ (SS) Jumlah skor minimum $=1 \times 7=7$ (TS) dengan presentase skor sebagai berikut : $\mathrm{P}=\frac{n}{\mathrm{~N}} \mathrm{X} 100 \%$

$\mathrm{P}=\frac{33}{35} \mathrm{X} 100 \%=94 \%$

Dari hasil penskoran ahli materi 1 mendapat $91 \%$ sedangkan ahli materi 2 mendapat $92 \%$ maka nilai rataratanya adalah

$$
\begin{aligned}
& x=\frac{1}{n} \sum_{i=1}^{n} x_{i} \\
& \mathrm{P}=\frac{1}{2}(91 \%+94 \%=92.5 \%=
\end{aligned}
$$

Secara keseluruhan nilai rata-rata game puzzle memproleh $92.5 \%$, dengan skor tersebut jika melihat pada tabel uji kelayakan termasuk dalam range $76 \%$ $100 \%$ yaitu sangat layak, konten materi yang ada dalam game puzzle sangat layak. 


\section{KESIMPULAN}

Berdasarkan hasil penelitian Pengembangan media pembelajaran fisika menggunakan game edukasi dapat digunakan sebagai media pembelejaran mata pelajaran fisika di kelas. Metode penelitian yang digunakan yaitu Research and Development dengan model pengembangan waterfall. Software pembuatan game edukasi ini dengan aplikasi Unity Game 3D dan aplikasi pendukung dengan Corel Draw dan android studio. Berdasarkan hasil uji kelayakan ahli media terhadap game puzzle, menunjukkan nilai rata-rata $83.2 \%$ maka, kesimpulan yang diambil bahwa game edukasi ini "Sangat Layak" dan menunjukkan hasil yang positif. Berdasarkan hasil uji kelayakan ahli materi pada game edukasi mata pelajaran fisika menunjukkan nilai rata-rata sebesar $92.5 \%$ maka, dapat disimpulkan bahwa materi game mata pelajaran fisika "Sangat Layak" untuk digunakan sebagai media pembelajaran.

\section{DAFTAR PUSTAKA}

[1] Ghavifekr, s., \& Rosdy, W. (2015). Teaching and learning with technology: Efectivieness of ICT integration in schools. International journal of research in education and science, Vol. 1. No. 2. hlm. 176-191.

[2] Kurnia, A. (2015). Pengaruh penggunaan media pembelajaran visual terhadap hasil belajar ekonomi siswa kelas $\mathrm{x}$ semester genap sma negeri 1 pekalongan. prosiding seminar nasional pendidikan ekonomi \& bisnis, $1-8$.

[3] Kasma, S., \& Prasti, D. (2020). Pengembangan Multimedia Interaktif Pembelajaran Instalasi Sistem Operasi Komputer Dengan Adobe Flash Cs6. Patria Artha Technological Journal, 4(1), 1-7

[4] Pressman, R. (2010). Software enginereing a practitioner's approach seventh edition. new york: Mc graw hill higer education.

[5] Putri, A. N., \& Syarif, I. (2019). Desain Media Pembelajaran Interaktif Berbasis Multimedia Dengan Aplikasi Sparkol Video Scribe. Patria Artha Technological Journal, 3(2), 102-108.

[6] Rizal, S. (2016). Media pembelajaran (panduan membuat presentasi menarik untuk pendidika dan peserta didik). Serang: CV. Nurani.

[7] Bakti, Rizki Yusliana, et al. "Game Edukasi Berbasis Android sebagai Media Pembelajaran Matematika untuk Anak Tunarungu." PROtek: Jurnal Ilmiah Teknik Elektro 8.1 (2021): 40-44..

[8] Sugiyono. (2015). Metode Penelitian Pendidikan (Pendekatan Kuantitatif, Kualitatif dan $R \& D$ ). Bandung: Alfabeta, Cv.

[9] Badruzzaman, M., Aribowo, D. A., \& Desmira, D. (2020). Game Edukasi pada Mata Pelajaran Dasar Listrik dan Elektronika Berbasis Android. PROtek: Jurnal Ilmiah Teknik Elektro, 7(2), 65-71

[10] Nurrahim, D. I., \& Sudarmilah, E. (2016). EduGame Sejarah Islam Masuk Indonesia. PROtek: Jurnal Ilmiah Teknik Elektro, 3(2), 57-62 